\title{
Adhesion of Arg-Gly-Asp (RGD) Peptide Vesicles onto an Integrin Surface: Visualization of the Segregation of RGD Ligands into the Adhesion Plaques by Fluorescence
}

\author{
Valérie Marchi-Artzner,*,t,‡ Barbara Lorz, † Charlie Gosse, ,,ll Ludovic J ullien,," \\ Rudolf Merkel, ${ }^{\dagger},{ }^{+}$Horst Kessler, ${ }^{\perp}$ and Erich Sackmann ${ }^{\dagger}$
}

Physik Department, Biophysik E22, Technische Universität München, J ames-Franck Strasse 1, D-85747 Garching, Germany, Laboratoire de Chimie des Interactions Moléculaires, UPR 285, Collège de France, 11 Place Marcel in Berthel ot, 75231 Paris Cedex 05, France, Ecole Normale Supérieure, Laboratoire de Physique Statistique, UMR 8550, 24 rue Lhomond,

75231 Paris Cedex 05, France, E cole Normale Supérieure, Département de Chimie, CNRS

UMR 8640, 24 rue Lhomond, 75231 Paris Cedex 05, France, Forschungszentrum J ülich,

Institute for Thin Films and Interfaces 4, D-52425 J ülich, Germany, and Institut für

Organische Chemie und Biochemie, Technische Universität München, Lichtenbergstrasse 4, D-85747 Garching, Germany

Received J uly 11, 2002. In Final Form: October 24, 2002

\begin{abstract}
I ntegrins are adhesion receptors that mediate cell adhesion and play an important function in many biological processes such as morphogenesis and tissue remodeling. These membrane proteins specifically interact with a short tripeptide sequence, RGD (Arg-Gly-Asp), present in numerous extracellular macromolecules. Model systems have been devel oped in order to understand how membrane adhesion is induced by this specific RGD peptide ligand/integrin recognition system. We have previously shown that RGD giant vesicles selectively adhere to endothelial cells by formation of pinning centers. Nevertheless, the nature of the lipids located in the adhesi on contact zone is unknown. One hypothesis is that the lipidic ligands migrate to the contact zone where they are confined after binding to the receptor. To study the possible formation of ligand domains within the vesicle bilayer, we synthesized a fluorescently labeled RGD lipid that can beeasily incorporated in giant vesicles. Adhesion of giant RGD vesicles ontoan integrinfunctionalized surface was followed simultaneously by reflection interference contrast microscopy and fluorescence microscopy. For the first time, it was possible to observe the microsegregation of RGD lipids in the contact zone during adhesion. Additionally, we observed interesting photosensitive properties of the chalcone chromophore that could lead to a new method of analyzing the lipid organization within the membrane during adhesion and to the design of new ligand lipids and veside vectors for cell targeting.
\end{abstract}

\section{Introduction}

Direct specific interactions between cells and between cells and extracellular matrixes arecritical tothefunction and the development of multicellular organisms. ${ }^{1}$ Cell adhesion to the extracellular matrix is mediated by transmembrane proteins called cell adhesion molecules (CAMs), which implicate specificinteractions sothat cells adhere only to other cells of certain types. The integrins form one group of such receptors, some of which also regulate cell-cell interactions (e.g., $\alpha \mathrm{V} \beta 1$ and VCAM). The integrins bind specifically to the Arg-Gly-Asp tripeptide (RGD), a short amino acid sequence present in several macromolecules of the extracellular matrix including fibronectin, collagen, and Iaminin. Lipid membranes bearing a RGD peptide headgroup have been built with the aim of better understanding the mechanism of membrane adhesi on via specific integrin/RGD molecular recognition systems ${ }^{2}$ and of designing new drug delivery

* Corresponding author. Tel: +3314427 1350. Fax: +33144 2713 56. E-mail: v.marchi-artzner@college-de-france.fr.

† Physik Department, Technische Universität München.

₹ UPR 285, Collège de France.

§ UMR 8550, Ecole Normale Supérieure.

" UMR 8640, Ecole Normale Supérieure.

$\perp$ Institut für Organische Chemie und Biochemie, Technische Universität München.

\# F orschungszentrum, J ülich.

(1) Chicurel, M. E.; Singer, R. H.; Meyer, C. J .; Ingber, D. E. Nature 1998, 392, 730-733. systems which may beabletotarget one specific cell type. In a previous paper, we described the selective adhesion between human endothelial cells and giant unilamellar vesicles (GUVs) containing a syntheticlipopeptidebearing a headgroup composed of the cyclic pentapeptide (c-ArgGly-Asp-\{Phe\}-Ala-Lys), called c(-RGDfK-). ${ }^{3}$ The advantage of a cyclic peptide compared to a linear peptide is that the constrained topology involves a selectivity for onesubtype of integrin $\left(\alpha_{v} \beta_{3}\right.$ or $\left.\alpha_{v} \beta_{5}\right) .{ }^{4}$ Recently thecrystal structure of the extracellular segment of theintegrin $\alpha_{v} \beta_{3}$ complexed with another cyclic pentapeptide (c-Arg-GlyAsp- $\{\mathrm{D}-\mathrm{Phe}\}-\{\mathrm{N}$-methyl-Val- $\}$ ) was determined. ${ }^{5}$ We previously observed that the adhesion of vesicles containing RGD lipids onto endothelial cells under a hydrodynamic shear flow induced theformation of pinning centers, which may be explained in terms of a lateral segregation of the ligands within the vesicle membrane and clustering of integrin receptors. The devel opment of selectiveadhesion, that is, an increasein the number of specificbonds between membranes, depends on the lateral mobility of the bond-

(2) Hu, B.; Finsinger, D.; Peter, K.; Guttenberg, Z.; Bärmann, M Kessler, H.; Escherich, A.; Moroder, L.; Böhm, J .; Baumeister, W.; Sui S.-F.; Sackmann, E. Biochemistry 2000, 39, 12284-12294.

(3) Marchi-Artzner, V.; Lorz, B.; Hellerer, U.; Kantlehner, M.; Kessler H.; Sackmann, E. Chem. Eur. J . 2001, 7 (5), 1095-1101.

(4) (a) Haubner, R.; Gratias, R.; Diefenbach, B.; Goodman, S. L.; J onczyk, A.; Kessler, H. J . Am. Chem. Soc. 1996, 118, 7461-7472. (b) Haubner, R.; Finsinger, D.; Kessler, H. Angew. Chem., Int. Ed. Engl. 1997, 36, 1374-1389.

(5) Xiong, J .-P.; Stehle, T.; Zhang, R.; J oachimiak, A.; Frech, M.; Gooodman, S. L.; Arnaout, M. A. Science 2002, 296, 151-155. 
forming species in the plane of the membrane. ${ }^{6}$ When the membranes come into contact, compl ementary molecules havetorecognizeeach other, and this is assumed to depend on their short-range diffusi on within the zone of contact. From a theoretical point of view, different mechanisms for lateral phase separation during the adhesion of multicomponent membranes have been proposed. ${ }^{7-9}$ The dependence of adhesion on local diffusion was pointed out in various model systems such as (i) rat basophilic leukemia (RBL) cells decorated with anti-dinitrophenyl (a-(DNP)) monoclonal IgE and vesicles exposing DNPlipid haptens ${ }^{10}$ (ii) membranes containing cationic lipids in contact with a negatively charged surface, ${ }^{11}$ (iii) membranes with biotinylated lipids interacting with a streptavidin-coated surface, ${ }^{12}$ and (iv) membranes with the homophilic cSA (contact site A) receptor from Dictyostelium discoideum. ${ }^{13}$ However, in all these systems, direct evidence of the ligand microsegregation into adhesion plaques was not provided. Recently however it was shown by themicropi pet aspi ration techniquethat a strong lateral attraction of the CSA receptors to the adhesion plaque occurs in vesicle-vesicle adhesion. ${ }^{14}$

In this paper, our aim is to detect a possible accumulation of RGD ligands in thezones of strong adhesion in the membrane by simultaneously using fluorescence microscopy and reflection interference contrast microscopy (RICM). First wedescribethe synthesis of a fluorescentlylabeled RGD lipopeptide which was incorporated into GUVs enabling the observation of the reorganization of the RGD-ligands in the adhesion zone. Then we present our results concerning the adhesion of giant vesicles containing fluorescent RGD lipids onto integrin-coated surfaces.

\section{Experimental Section}

Materials. All reagents and solvents were at least analytical grade and were used as supplied. The dioleoylphosphatidylcholine (DOPC), 1,2-dimyristoyl-sn-glycero-3-phosphatidylcholine (DM PC), 1,2-dimyristoyl-sn-glycero-3-phosphatidylethanolamine-N-[poly(ethyleneglycol ) 2000] (PEG $2000-D M P E)$, and cholesterol (Chol) were purchased from Avanti. HATU ${ }^{15}$ was purchased from Biosystems Perseptive $\mathrm{GmbH}$. The cyclic pentapeptides c(-R(Pbf)GD (OtBu)fK-) and c(-RGDfK -) were prepared as follows: ${ }^{4 b}$ after thecyclization of thesidechain protected linear precursor $\mathrm{C}\left(-\mathrm{R}(\mathrm{Pbf}) \mathrm{GD}\left(\mathrm{O}^{\mathrm{t}} \mathrm{Bu}\right) \mathrm{fK}(\mathrm{Z})-\right.$ ) synthesized by solid-phase synthesis via the F moc strategy, ${ }^{16}$ the temporary Z-protecting group for lysinewas d eaved by hydrogenolysis on a Pd/C catalyst. Pbf and tBu can becleaved by a TFA/C $\mathrm{HCl}_{3}$ (95:5) mixture. ${ }^{17} \mathrm{All}$ thereactions weremonitored by thin-layer chromatography using

(6) Dustin, M. L.; Ferguson, L. M.; Chan, P.Y.; Springer, T. A.; Golan, D. E. J . Cell. Biol. 1996, 132, 465-477.

(7) Weikl, T. R.; Lipowsky, R. Phys. Rev. E 2001, 64, 011903/13.

(8) Komura, S.; Andelman, D. Eur. Phys. J . 2000, E3, 259-271.

(9) Bruisma, R.; Sackmann, E. C. R. Acad. Sci., Ser. IV 2001, 2, 803-815.

(10) McCloskey, M.; Mu-ming, P. J . Cell. Biol. 1986, 102, 21852196.

(11) Nardi, J .; Feder, T.; Sackmann, E. Europhys. Lett. 1997, 37, 371-376 and erratum 38, 159-160.

(12) Albersdörfer, A.; Feder, T.; Sackmann, E. Biophys. J . 1997, 73, 245-257.

(13) Kloboucek, A.; Behrisch, A.; Faix, J .; Sackmann, E. Biophys. J . 1999, 77, 2311-2328.

(14) Maier, C.; Behrisch, A.; Kloboucek, A.; Simson, D. A.; Merkel, R. Eur. Phys. J.E 2001, 6 (4), 273-276.

(15) Abbreviations: BSA, bovine serum albumin; Fmoc: 9-fluore nylmethoxycarbonyl; Pbf, 2,2',4,5,7-pentamethyl-3-hydrobenzofuran6-sulfonyl; HATU, hexafluorophosphate o-(7-azabenzotriazol-1-yl)1,1,3,3-tetramethyl-uronium; NBD, nitrobenz-2-oxa-1,3-diazole; OG, n-octyl $\beta$-D-glucopyranoside.

(16) Fields, G. B.; Noble, R. L. Int. J . Pept. Protein Res. 1990, 35, $161-214$

(17) Finsinger, D. Ph.D. Thesis, Technical University Munich, Munich, Germany, 1997.
$0.25 \mathrm{~mm}$ silica gel plates (Merck). Column chromatography was performed using silica gel-60 (Merck, 230-400 mesh ASTM). NMR spectra were recorded on a Bruker AM-200 spectrometer (200 M Hz). High-performance liquid chromatography (HPLC) was performed using an analytical and a semi preparative col umn Si-60.

Synthesis of the RGD Fluorescent Lipid. Chalcone Acid 3. $\mathrm{EO}_{3}$ chalcone $1^{18}(1.00 \mathrm{~g}, 1.22 \mathrm{mmol}, 1$ equiv) and ethyl diazoacetate $(0.153 \mathrm{~g}, 1.34 \mathrm{mmol}, 1.1$ equiv) were dissol ved in anhydrous dichloromethane $(10 \mathrm{~mL})$. Trifluoroboroetherate (3 drops) was then added. The solution turned from a yellow to a red color upon addition of the $\mathrm{BF}_{3} \mathrm{OEt}_{2}$ catalyst. The mixture was stirred at room temperature for $36 \mathrm{~h}$ under argon. After purification on a silica column (eluent AcOEt, $\mathrm{Rf}=0.9$ ), theester 2 (122 mg, $0.134 \mathrm{mmol}$, yield $11 \%)$ was isolated. ${ }^{1} \mathrm{H}$ NMR (200 $\left.\mathrm{MHz} \mathrm{CDCl}_{3}\right): \delta=7.95(\mathrm{~d}, \mathrm{~J}(\mathrm{H}, \mathrm{H})=8 \mathrm{~Hz}, 2 \mathrm{H}), 7.73(\mathrm{~d}, \mathrm{~J}$ trans $(\mathrm{H}, \mathrm{H})=15 \mathrm{~Hz}, 1 \mathrm{H}), 7.47(\mathrm{~d}, \mathrm{~J}(\mathrm{H}, \mathrm{H})=8 \mathrm{~Hz}, 2 \mathrm{H}), 7.27(\mathrm{~d}, \mathrm{~J}$ trans $(\mathrm{H}, \mathrm{H})=15 \mathrm{~Hz}, 1 \mathrm{H}), 6.92(\mathrm{~d}, J(\mathrm{H}, \mathrm{H})=8 \mathrm{~Hz}, 2 \mathrm{H}), 6.57(\mathrm{~d}, \mathrm{~J}(\mathrm{H}, \mathrm{H})$ $=8 \mathrm{~Hz}, 2 \mathrm{H}), 4.15(\mathrm{~s}, 2 \mathrm{H}), 3.81(\mathrm{t}, \mathrm{J}(\mathrm{H}, \mathrm{H})=7 \mathrm{~Hz}, 2 \mathrm{H}), 3.68-3.45$ $(\mathrm{m}, 10 \mathrm{H}), 3.26(\mathrm{t}, \mathrm{J}(\mathrm{H}, \mathrm{H})=8 \mathrm{~Hz}, 4 \mathrm{H}), 1.55(\mathrm{~m}, 4 \mathrm{H}), 1.35-1.1$ $(\mathrm{m}, 55 \mathrm{H}), 0.84(\mathrm{t}, 6 \mathrm{H})$. The ester 2 was then saponified in a 10 $\mathrm{mM} \mathrm{NaOH}$ solution in ethanol for $36 \mathrm{~h}$ at room temperature. After neutralization and filtration on a silica column (eluent $\mathrm{CH}_{2} \mathrm{Cl}_{2} / \mathrm{MeOH}$ 9:1, $\left.\mathrm{Rf}=0.25\right)$, the acid derivative 3 (100 mg, $0.114 \mathrm{mmol}$, yield $9 \%)$ was isolated. ${ }^{1} \mathrm{H} \mathrm{NMR}\left(200 \mathrm{MHz} \mathrm{CDCl}_{3}\right)$ : $\delta=7.90(\mathrm{~d}, \mathrm{~J}(\mathrm{H}, \mathrm{H})=8 \mathrm{~Hz}, 2 \mathrm{H}), 7.73(\mathrm{~d}, \mathrm{~J}$ trans $(\mathrm{H}, \mathrm{H})=15 \mathrm{~Hz}$, $1 \mathrm{H}), 7.47(\mathrm{~d}, \mathrm{~J}(\mathrm{H}, \mathrm{H})=8 \mathrm{~Hz}, 2 \mathrm{H}), 7.27(\mathrm{~d}, \mathrm{~J}$ trans $(\mathrm{H}, \mathrm{H})=15 \mathrm{~Hz}$, $1 \mathrm{H}), 6.94(\mathrm{~d}, \mathrm{~J}(\mathrm{H}, \mathrm{H})=8 \mathrm{~Hz}, 2 \mathrm{H}), 6.57(\mathrm{~d}, J(\mathrm{H}, \mathrm{H})=8 \mathrm{~Hz}, 2 \mathrm{H})$, $4.15(\mathrm{~s}, 2 \mathrm{H}), 3.81-3.51(\mathrm{~m}, 10 \mathrm{H}), 3.27(\mathrm{t}, \mathrm{J}(\mathrm{H}, \mathrm{H})=8 \mathrm{~Hz}, 4 \mathrm{H})$, $1.55(\mathrm{~m}, 4 \mathrm{H}), 1.35-1.1(\mathrm{~m}, 55 \mathrm{H}), 0.84(\mathrm{t}, 6 \mathrm{H})$. MS calculated: 877.7; found: $878.5\left[\mathrm{M}^{+}+\mathrm{H}\right]$.

$\mathrm{C}\left(-\mathrm{R}(\mathrm{Pbf}) \mathrm{GD}\left(\mathrm{O}^{\mathrm{t}} \mathrm{Bu}\right) \mathrm{fK}-\right)$ Chal cone4. Theacid 3(30 mg, $34 \mu \mathrm{mol}$ 1 equiv), $c\left(-R(P b f) G D\left(O^{t} B u\right) f K-\right)$ ( $35 \mathrm{mg}, 38 \mu \mathrm{mol}, 1.1$ equiv), HATU (14.5 mg, $38 \mu \mathrm{mol}, 1.1$ equiv), and collidine ( $9 \mu \mathrm{L}, 68 \mu \mathrm{mol}$, 2 equiv) were mixed together in anhydrous DMF $(1 \mathrm{~mL})$ and maintained under argon for $6 \mathrm{~h}$. After elimination of DMF and purification on two successivesilica plates (eluent $\mathrm{CH}_{2} \mathrm{Cl}_{2} / \mathrm{MeOH}$ 9:1, $\mathrm{Rf}=0.45$ ) followed by purification by $\mathrm{HPLC}$ (eluent: $\mathrm{MeOH}$ gradient from $10 \%$ to $30 \%$ in $\mathrm{CH}_{2} \mathrm{Cl}_{2}$ ), pure product 4 was isol ated (40 mg, $23 \mu \mathrm{mol}$, yield 66\%). MS calculated: 1771.13; found: $1171.5\left[\mathrm{M}^{+}\right], 1772.5\left[\mathrm{M}^{+}+\mathrm{H}\right]$. Microanalysis calculated for $\mathrm{C}_{99} \mathrm{H}_{154} \mathrm{~N}_{10} \mathrm{O}_{16} \mathrm{~S}, \mathrm{H}_{2} \mathrm{O}: 66.41(\% \mathrm{C}), 8.78(\% \mathrm{H}), 7.82(\% \mathrm{~N})$; found: $66.19(\% \mathrm{C}), 8.69(\% \mathrm{H}), 7.72(\% \mathrm{~N})$.

C(-RGDfK-) Chalcone Lipid 5. The chalcone lipopeptide 4 was deprotected by diluted TFA $\left(\mathrm{CHCl}_{3} / \mathrm{TFA}\right.$ 95:5). After crystallization, washing in $\mathrm{MeOH}$, and centrifugation at $0^{\circ} \mathrm{C}$, theproduct 5(17 mg, $7 \mu \mathrm{mol}$, yiel d 30\%) was isolated. MS calculated: 1462.98 $\left[\mathrm{M}^{+}\right]$; found: $1463.7\left[\mathrm{M}^{+}+\mathrm{H}\right]$.

Preparation of the Integrin-F unctionalized Surfaces. The $\alpha_{\text {IIb }} \beta_{3}$ integrin was isolated from human blood platelets according to the method of Fitzgerald et al. modified by $\mathrm{Hu}$ et al. ${ }^{2}$ Glass substrates werethen coated by $\alpha_{|l|} \beta_{3}$ integrin according to the procedure previously described. ${ }^{19}$ The $\alpha_{11 b} \beta_{3}$ integrin proteins, solubilized in S300 buffer containing $20 \mathrm{mM}$ Tris $\mathrm{pH}$ 7.25, $150 \mathrm{mM} \mathrm{NaCl}, 1 \mathrm{mM} \mathrm{NaN}_{3}, 1 \mathrm{mM} \mathrm{CaCl}_{2}$, and $1 \mathrm{mM} \mathrm{MgCl}_{2}$ completed with $0.01 \%$ Triton $\mathrm{X}-100$, were filtered through a 0.2 $\mu \mathrm{m}$ Nudeopore filter. The $\alpha_{1 \mathrm{lb}} \beta_{3}$ integrin solution $(900 \mu \mathrm{L})$ was then spread on a coverslip and incubated for $1 \mathrm{~h}$ before repeated washing (6times) with S1 buffer containing 10 mM HEPES, 100 $\mathrm{mM} \mathrm{NaCl}, 1 \mathrm{mM} \mathrm{NaN}_{3}$, and $1 \mathrm{mM} \mathrm{CaCl}_{2}$ (osmolarity, $210 \mathrm{mOsm}$ ). To prevent nonspecific adhesion, the integrin surface was subsequently incubated with BSA protein: as for integrin, a solution containing $3 \%$ of BSA protein $(900 \mu \mathrm{L})$ in S1 buffer was filtered and incubated on the coverslip before washing 6 times with buffer.

Preparation of the RGD-Doped GUVs. Giant vesicles were prepared by the method of electric swelling. ${ }^{20}$ The lipids were dissolved in a (9:1) chloroform-methanol solution, and the solution was spread onto a cover slide covered by indium-tin oxide (ITO) electrodes. A (50:50:3) mixture of chol esterol, DMPC,

(18) Gosse, C. Ph.D. Thesis, Pierre et Marie Curie University, Paris VI, France, 1999.

(19) Guttenberg, Z. Ph.D. Thesis, Technical Universität Munich, Munich, Germany, 2000.

(20) Angelova, M. I.; Dimitrov, D. S. Mol. Cryst. Liq. Cryst. 1987, $152,89$. 


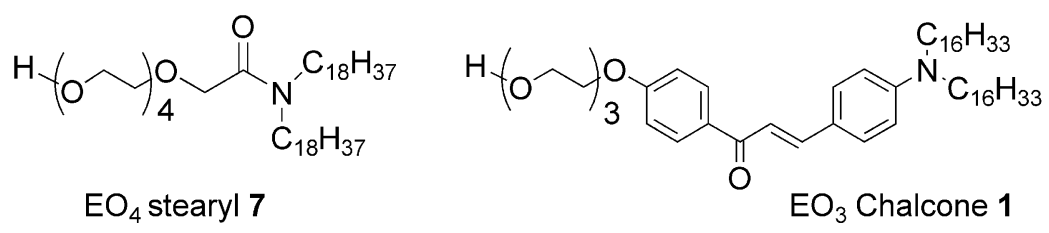

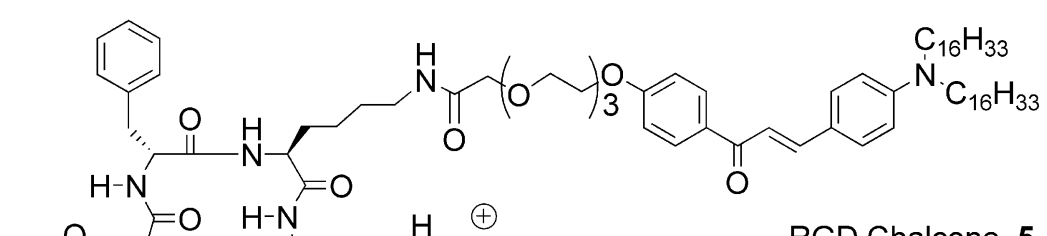

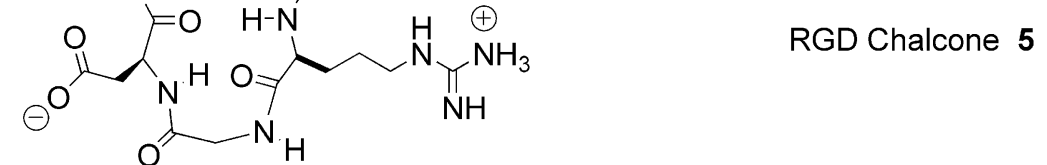

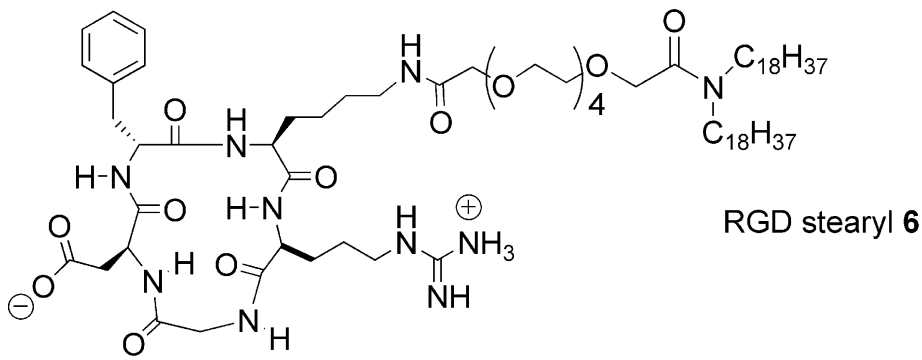

Figure 1. Chemical structures of thevarious syntheticlipids used in our study. They are either labeled by thechal conechromophore or not and bear either an RGD peptide headgroup or a control hydroxyl group.

and PEG $\mathrm{F}_{200}-\mathrm{DM} P E$ was used as a lipid matrix and completed with (i) 2 mol \% RGD chalcone 5 or (ii) 2 mol \% RGD stearyl 6 and $2 \mathrm{~mol} \% \mathrm{EO}_{3}$ chalcone 1 . After drying under vacuum, the coverslips were placed in a closed cell. Vesicles were swollen in a $180 \mathrm{mM}$ sucrose solution containing $0.01 \mathrm{~mol} \%$ sodium azide; a $10 \mathrm{~Hz}$ ac field $(20 \mathrm{~V} / \mathrm{cm})$ was applied for $2 \mathrm{~h}$.

RICM and Fluorescence Microscopy. Suspensions of the GUVs $(100 \mu \mathrm{L})$ were diluted with S1 buffer $(900 \mu \mathrm{L})$ and then deposited ontothereceptor-coated coverslip. Thevesi cleadhesi on totheintegrin-functionalized surfaces was monitored with a Zeiss Axiovert 100S microscope equipped with an antiflex objective (Plan-Neofluar 63x; numerical aperture 1.25; oil immersion) at room temperature. ${ }^{21} \mathrm{~A}$ high-pressure mercury arc lamp (Osram HBO 100) was used as thelight source. Fluorescence was excited and observed by the appropriate filter sets. The $546 \mathrm{~nm}$ line of the mercury arc lamp was used for the RICM technique. This all owed us to observethesamesample by both microfluorescence and RICM. A CCD camera (C2400-75i controlled by an Argus 20 image acquisition system, Hamamatsu) that integrates intensities over variable intervals of time permits observation of weak fluorescence signals. The video camera records 25 images per second.

Monolayer Study. A custom-designed film balancecombined with a fluorescent microscope was used to observe the lateral organization of the lipid monolayer by microfluorescence. The temperature was maintained at $20^{\circ} \mathrm{C} .22$

\section{Results}

Synthesis of the Fluorescent c(-R GDfK-) Lipopeptide. To visualize the reorganization of the RGD lipid during the adhesion process through RGD-integrin interaction, we synthesized fluorescently labeled lipids with and without the RGD headgroup. Their chemical structures are presented in Figure 1.

As a chromophore, we chose a chalcone group which was previously used for the labeling of hydrophobic oligonucleotides in order to study their interaction with

(21) Rädler, J .; Sackmann, E. J . Phys. II France 1993, 3, 727-748. (22) Heyn, S. P.; Tillmann, R. W.; Egger, M.; Gaub, H. E.J . Biochem. Biophys. Methods 1991, 22, 145-158. model membranes. ${ }^{23}$ Compared to other conventional chromophores such as NBD used for the labeling of amphiphilic dextran polymers, ${ }^{24}$ this inexpensivechal cone can be prepared in large quantities and can bederivatized to couple with various functional groups. In view of its structure, it is rather unambiguously located within the lipid bilayer after membrane insertion. In addition, it possesses suitablephotophysical properties that al ow the detection of its fluorescencewith commercial fluorescence filters for optical microscopy $\left(\lambda_{\text {exc }} \cong 410 \mathrm{~nm}\right.$; width at halfheight of the absorption peak $\cong 70 \mathrm{~nm} ; \lambda_{\text {em }} \cong 550 \mathrm{~nm}$ ). ${ }^{25}$ $\mathrm{TheEO}_{3}$ chal cone 1 can be used as a probefor membranes. In fact, solvatochromic properties originating from its donor-acceptor structure facilitate its location in the investigated systems.

A RGD lipid bearing a chalcone chromophore in the alkyl chain was prepared by following the routeshown in Figure 2. The $\mathrm{EO}_{3}$ chalcone 1, synthesized according to the previously described procedure, ${ }^{23}$ was converted to the ester $\mathbf{2}$ by reaction with ethyl diazoacetate. The low yield of this reaction could be due to the complexation of the catalyst by the chalcone group as revealed by a color change. After saponification, the acid 3 was condensed to the partially protected cycl ic peptide c(-R(Pbf)GD(OtBu)fK-) using the free amino group of the lysine residue to give the amide $\mathbf{4}$ with the peptide-coupling reagent HATU. ${ }^{26}$ The product 4 could be purified efficiently by HPLC and then deprotected by TFA to give the RGD chalcone 5. The synthesis of the nonlabeled RGD stearyl 6 and $\mathrm{EO}_{4}$ stearyl 7 lipids was previously reported. ${ }^{3}$

(23) Gosse, C.; Boutorine, A. S.; J ullien, L.; Hélène, C. Nucleosides Nucleotides 1999, 18 (6\&7), 1473-1476.

(24) Tsafrir, I.; Guedeau-Boudeville, M. A.; Kandel, D.; Stavans, J . Phys. Rev. E 2001, 63, 031603-1,11.

(25) Bernard, A. L.; Guedeau-Boudeville, M. A.; J ullien, L.; di Meglio, J . M. Langmuir 2000, 16, 6809-6820.

(26) Carpino, L. A.; El-Faham, A.; Albericio, F. Tetrahedron Lett. 1994, 35, 2279-2282. 
1

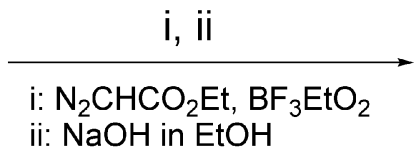<smiles>[R]OC(=O)CCOc1ccc(C(=O)/C=C/c2ccc(NC)cc2)cc1</smiles>

HATU, collidine, $\mathrm{KR}(\mathrm{Pbf}) \mathrm{GD}(\mathrm{OtBu}) \mathrm{F}$
$\mathrm{C}_{16} \mathrm{H}_{33}$

$\mathrm{N}_{-} \mathrm{C}_{16} \mathrm{H}_{33}$

2: $\mathrm{R}=\mathrm{CH}_{3} \mathrm{CH}_{2}$ (i)

3: $\mathrm{R}=\mathrm{H}$

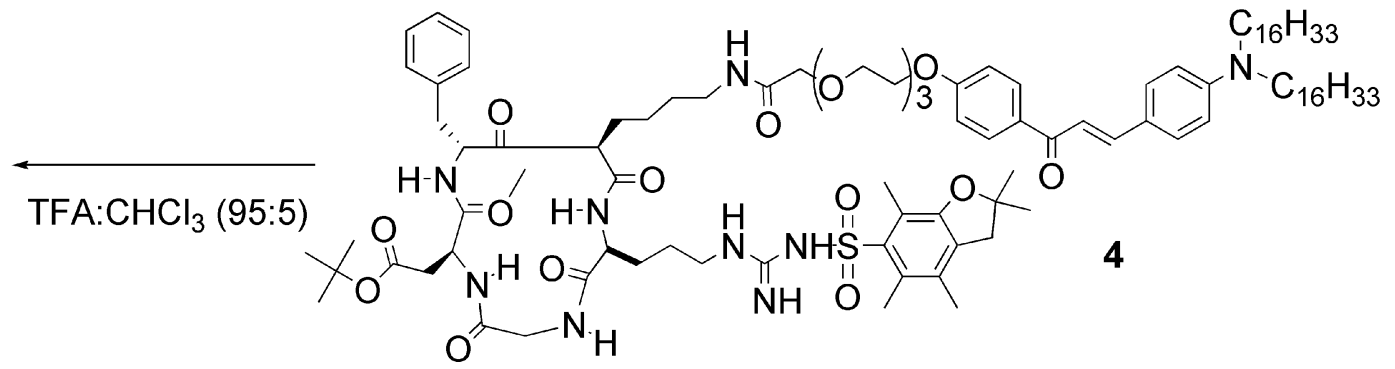

Figure 2. Synthetic route followed for the preparation of the RGD chalcone $\mathbf{5}$ from the $\mathrm{EO}_{3}$ chalcone $\mathbf{1}$

Phase Behavior in a Monolayer. To analyze the phenomena occurring during vesicle adhesion, we investigated the phasebehavior of puresyntheticchal conelipids and the lipid mixture used for vesicle preparation. Particular attention was paid to possiblephaseseparation in the vesicle bilayer. In fact, such behavior can be significant if the enthalpy of pinning centers formation can balance the entropic cost associated with a local concentration increase. Pressure-area isotherms of the monol ayers of theinvestigated lipid systems wererecorded by using a Langmuir film balance combined with a setup for fluorescent mi croscopy. The pressure-area isotherms of the monolayer made of pure $\mathrm{EO}_{3}$ chalcone 1 and RGD chalcone $\mathbf{5}$ as well as those of RGD stearyl $\mathbf{6}$ and $\mathrm{EO}_{4}$ stearyl $\mathbf{7}$ are presented in Figure 3a.

The $\mathrm{EO}_{3}$ chalcone $\mathbf{1}$ monolayer exhibited a plateau corresponding to a first-order transition that could probably be attributed to a transition of the hexadecyl chains from an expanded liquid to a condensed phase, which is consistent with the behavior of the similar $\mathrm{EO}_{4}$ stearyl 7. In the case of the RGD chal cone 5, no such transition was observed in contrast to the case of RGD stearyl $\mathbf{6}$. The absence of a transition to a crystalline state in $\mathbf{5}$ was probably related tothedisorder introduced by thechalcone chromophore.

For the giant vesicle preparation, a mixture of DMPC/ cholesterol/PEG 2000 -DMPE (50:50:1) was used. The lipopolymer promotes theformation of GUVs in the presence of the buffer. Moreover, theaddition of $1 \mathrm{~mol} \%$ of $P E_{2000}-$ DMPE impeded the nonspecific adhesion of the vesicles to the surface. The isotherm of the monolayer containing 2 mol \% RGD chalcone 5 did not exhibit any plateau. ${ }^{27}$ Epifluorescence microscopy images were recorded during the compression of themonolayer. As shown in Figure 3b, one can observe foamlike microdomains that are either depleted or enriched with chalconelipid. When thesurface pressure was increased, the observed dark domains merged and grew. It was previously reported that similar fluid phases coexist in cholesterol/DM PC mixtures at low surface pressure. ${ }^{28}$

(27) In contrast to the isotherm of the monolayer containing $2 \% \mathrm{~mol}$ EO 3 chal cone 1 and 2 mol \% RGD stearyl 6 (see Figure A in Supporting Information). In thelatter case, the presence of a plateau indicates that a first-order transition occurs as observed in the case of a monolayer of pure $\mathrm{EO} 3$ chalcone 1.
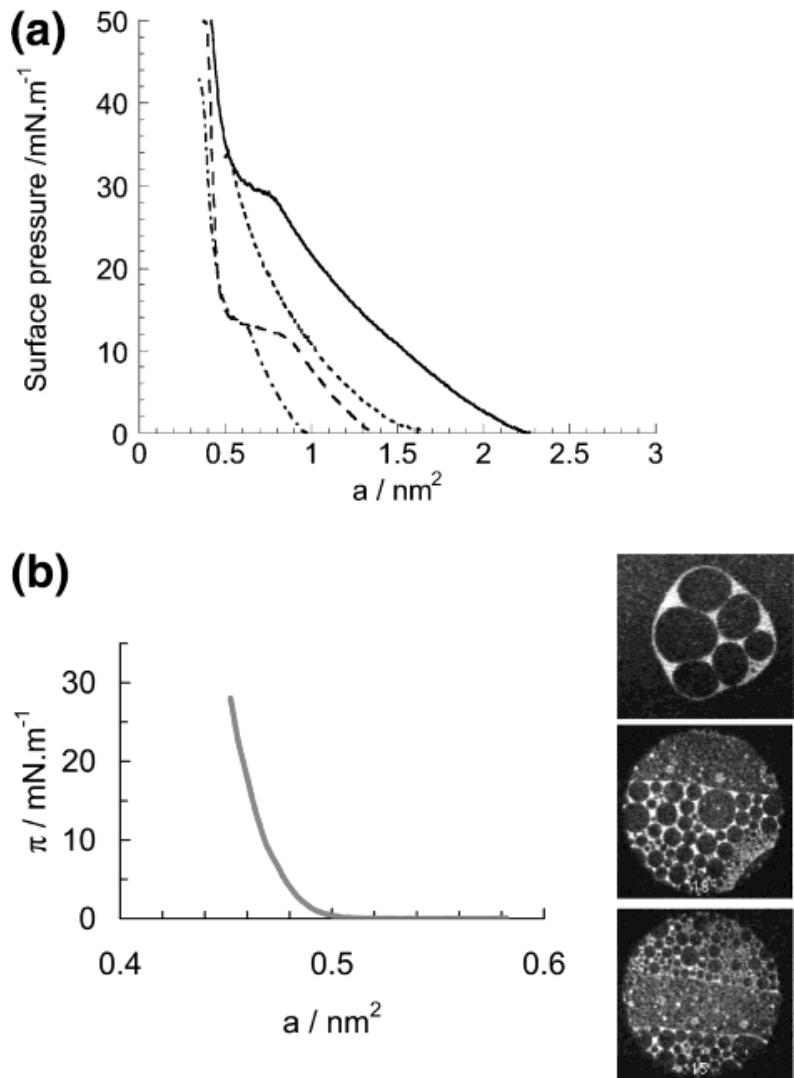

Figure 3. (a) Langmuir isotherms of a monolayer composed of RGD stearyl $\mathbf{6}$ (solid line), RGD chal cone $\mathbf{5}$ (dotted line), $\mathrm{EO}_{3}$ chalcone $\mathbf{1}$ (dotted-dashed line), and $\mathrm{EO}_{4}$ stearyl $\mathbf{7}$ (dashed line). (b) Langmuir isotherms of a monolayer composed of RGD chalcone $\mathbf{5}(2 \% \mathrm{~mol})$ in a matrix of DMPC/cholesterol/DMPE $\mathrm{PEG}_{2000}$ (50:50:1) and images obtained from optical epifluorescence microscopy at a surface pressure of 35, 14, and $9 \mathrm{mN}$ $\mathrm{m}^{-1}$ (from top to bottom).

The present results show that the lipid mixture used for the GUV experiments exhibited the coexistence of domains both rich and poor in fluorescent lipid in the Langmuir monol ayer even at a surface pressure of $35 \mathrm{mN}$

(28) Möhwald, H. In Handbook of Biological Physics: Structures and Dynamics of Membranes; Lipowski, R., Sackmann, E., Eds.; Elsevier: Amsterdam, 1995; Vol. 1, p 198 and references therein. 


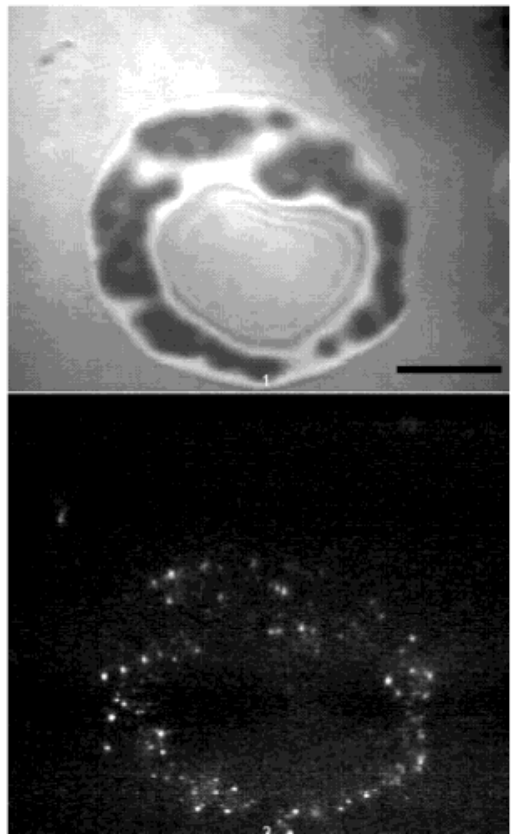

Figure 4. Typical image of a stably adhering vesi de containing RGD chalcone 5 (2 mol \%) in matrix DMPC/Chol/DMPE$\mathrm{PEG}_{2000}$ (50:50:3) ( $\alpha_{11 \mathrm{~b}} \beta_{3}$ integrin surface): (top) by RICM and (bottom) by fluorescence optical microscopy $\left(\lambda_{\text {exc }}=450\right)$. The fluorescence image was obtained from accumulation of several recorded video images (one image every $40 \mathrm{~ms}$ during $500 \mathrm{~ms}$ ) before the fast bleaching of the probe (around $100 \mathrm{~ms}$ ). N otice that all the fluorescent spots are localized in the contact zone. The scale bar represents $10 \mu \mathrm{m}$.

$\mathrm{m}^{-1}$. Consequently, this suggests that someheterogeneity in the distribution of the lipid components within the vesiclebilayer can occur. Nevertheless, theRGD chalcone 5 could be preferentially incorporated within the most liquid parts of the membrane.

Adhesion onto an Integrin-Functionalized Surface. To investigate the importance of the lateral redistribution of RGD ligands within a vesiclemembranebound to an immobilized integrin receptor, an adhesion-mimicking system composed of RGD giant vesicles (GUVs) and surfaces presenting adsorbed but functional $\alpha_{11 \mathrm{~b}} \beta_{3}$ integrin was designed. We prepared giant vesicles containing 2 mol \% of the RGD chalcone 5 and observed their adhesion onto a $\alpha_{11 b} \beta_{3}$ integrin surface. ${ }^{29}$ This smooth bi ofunctional surface is more appropriate than surfaces coated with endothelial cells for adhesion studies because the surface roughness of the cells complicates the adhesion plaque observation by RICM.

To observe the distribution of the fluorescent ligand in the contact zone, we used a microscope enabling both RICM ${ }^{21}$ and fluorescence microscopy observations. After $30 \mathrm{~min}$ of incubation, vesicles containing 2 mol \% RGD chalcone $\mathbf{5}$ adhered efficiently onto an integrin-covered surface as manifested by the black zones of contact in the RICM images (Figure 4a). The vesicleshapein thevicinity of the contact zone is delimited by thearray of Newtonian fringes. I n addition, dark zones appear within theadhesion disk which are attributed to areas of strong adhesion. Once the RICM image of the adhered vesicle remains stabilized, the location of the RGD chalcone lipid $\mathbf{5}$ was visualized by fluorescence microscopy. Upon a short irradiation of the adhered vesicles (about $500 \mathrm{~ms}$ ), one can clearly observe fluorescent spots which are concen-

(29) Boulbitch, A.; Gutenberg, Z.; Sackmann, E. Biophys. J . 2001, $81,2743-2751$

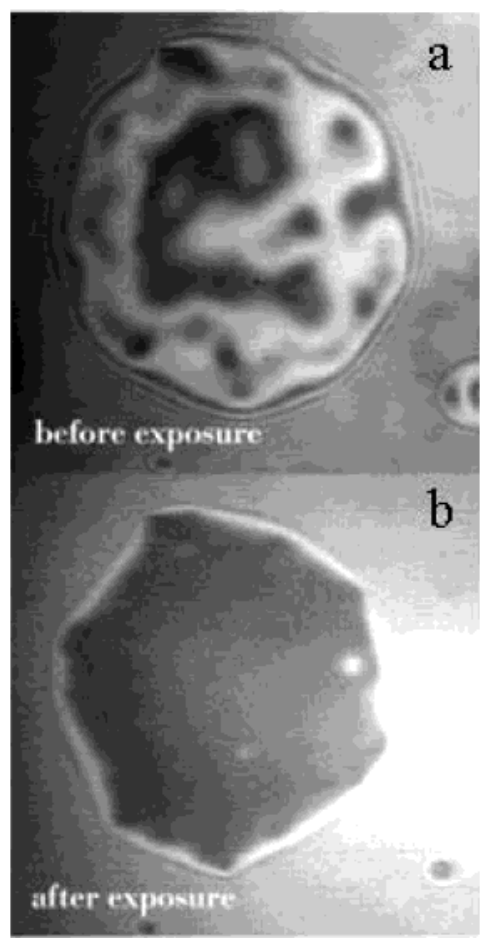

Figure 5. Typical RICM image of an adhering veside containing RGD chal cone 5 (2 mol \%) in a matrix DMPC/cholesterol/ DMPE $-\mathrm{PEG}_{2000}$ (50:50:1): images taken (top) beforeirradiation and (bottom) after irradiation. Notice that the adhesion is strongly reinforced by irradiation (exposure time of about $30 \mathrm{~s}$ ). The scale is the same as in Figure 4.

trated in the adhesion zone appearing as a black zone in RICM as shown in Figure 4b. As a control experiment, GUVs containing 2 mol \% of $\mathrm{EO}_{3}$ chal cone 1 were prepared. These were not found to adhere onto the integrin surface. Furthermore, the fluorescence of these vesicles was homogeneously distributed on the contour of the vesicle. This observation al ready provides unambiguous evidence for the correlation between the location of the RGD chal cone 5 within the membrane and the sites where the bilayer adheres to the integrin-derivatized surface.

Two other remarkable features emerged during this series of experiments. First, when the RGD chalcone $\mathbf{5}$ vesicles are adhered onto an integrin-functionalized surface, thefluorescent spots corresponding tothechalcone chromophore disappear ed after a very short characteristic time of exposure (about $100 \mathrm{~ms}$ ). For comparison, the fluorescence of the same GUV in absence of the adhesive integrin surface or the fluorescence of a nonadhesive $\mathrm{EO}_{3}$ chalcone 1 vesicle can be observed during at least $10 \mathrm{~s}$. Additionally, the same experiment was carried out with giant vesicles containing 2 mol \% $\mathrm{EO}_{3}$ chalcone $\mathbf{1}$ and 2 mol \%nonfluorescently labeled RGD stearyl 6. Under the sameconditions, thesevesicles still adhered totheintegrin surface. But in contrast to RGD chal cone 5 GUVs, upon irradiation of thesample, their fluorescence was bleached with a characteristic time that was slower by 2 orders of magnitude (about $20 \mathrm{~s}$ )

Second, we found that adhesion of vesicles containing 2 mol \% RGD chalcone 5 onto the integrin surface became surprisingly much stronger after a 30 s irradiation with the lamp used for fluorescence observation. This was concluded from the large increase of the black area in RICM images after exposure (compare Figure 5a before irradiation with Figure 5b after irradiation). Obviously the system inducing the adhesion process was modified during the irradiation and became more efficient in the adhesion onto the integrin surface. 
To elucidate the mechanism of fluorescence decrease observed during the vesicle adhesion, we carried out two further experiments. Weobserved thefluorescencechange of a solution of a $\mathrm{EO}_{3}$ chalcone $\mathbf{1}(12.1 \mu \mathrm{M})$ in various solutions of OG detergent (see Figure $B$, Supporting Information). When the concentration of OG in thesolution was increased, the fluorescence of $\mathrm{EO}_{3}$ chalcone $\mathbf{1}$ was increased. This observation was attributed tothe di lution of $\mathbf{1}$ in the mixed OG/1 micelles resulting in a decrease of its self-quenching. In a second experiment, the kinetics of thefluor escence bleaching of a solution of $\mathrm{EO}_{3}$ chal cone 1 was compared in the case of a 1:10 mixture of 1 and OG (where 1 is self-quenched) and in the case of a 1:2000 mixture of $\mathbf{1}$ and OG (above the critical micelle concentrati on of OG, around $20 \mathrm{mM},{ }^{30}$ where 1 is not self-quenched) (see Figure C, Supporting Information). The observed characteristic time was the same for the two samples. Ther efore, the observed bleaching does not depend on the surface concentration of $\mathbf{1}$ in OG micelles and is only due to the monomer $\mathrm{EO}_{3}$ chalcone.

\section{Discussion}

In these experiments, the fluorescence spots observed duringthevesicleadhesion ontotheintegrin surfaceshow that the chal cone lipids are concentrated in the adhesion plaques. These experiments also show a specific behavior of the RGD chalcone 5 in pinning centers. Theirradiation causes a faster bleaching of the chalcone chromophore affecting the adhesive properties of the vesicle onto the integrin surface. This behavior is related to the very high concentration of RGD chalcone $\mathbf{5}$ in the contact zone. Indeed, one can envisage that the chalcone fluorescence is self-quenched due to its high concentration in the adhesion zone. However, weobserved that the kinetics of the photodestruction of the chal cone monomer in a $\mathbf{1 / O G}$ micellar solution was the same whether there was selfquenching of $\mathbf{1}$ (1:10 mixture) or not (1:2000). If the very short bleaching time observed for the RGD chalcone 5 adhered vesicles was due to a self-quenching of the chalcone monomer like the one observed in OG micelles, it should be the same as that observed for nonadhered RGD chalcone $\mathbf{5}$ vesicles or $\mathrm{EO}_{3}$ chalcone $\mathbf{1}$ vesicles in solution. Instead of that, we observed a significant difference in the quenching time so that one can exclude a self-quenching of the chalconemonomer for theadhered RGD chalcone $\mathbf{5}$ vesicles, due to its high concentration in the adhesion plaques. A second mechanism can be envisaged to explain the behavior of the RGD chalcone 5 during vesicle adhesion.

The characteristic short time for fluorescence decrease is in agreement with a photoreaction of the chalcone. It is known from the literature that the chalcone is highly photosensitive. Thus irradiation of chalcone groups can lead to a nonfluorescent cyclobutane dimer through a [2 +2 ] cyclodimerization. This process is normally observed in the solid state where the two implicated double bonds haveto be parallel and separated by a few angströms. ${ }^{31,32}$ To form this chalcone dimer, the local concentration in chalconelipid has tobevery high. TheRGD chal coneseems to stay in the fluid phase as suggested by the monolayer study so that its migration within the membrane is not limited by the viscosity or by percolation. In the contact zone, the RGD chalcone groups are expected to form

(30) Lasic, D. D. Liposomes: From Physics to Applications; Elsevier: Amsterdam, 1993.

(31) Montaudo, G.; Caccamese, S. J . Org. Chem. 1973, 38 (4), 710716

(32) Green, B. S.; Lahav, M.; Rabinovich, D. Acc. Chem. Res. 1979, 12, 191-197.

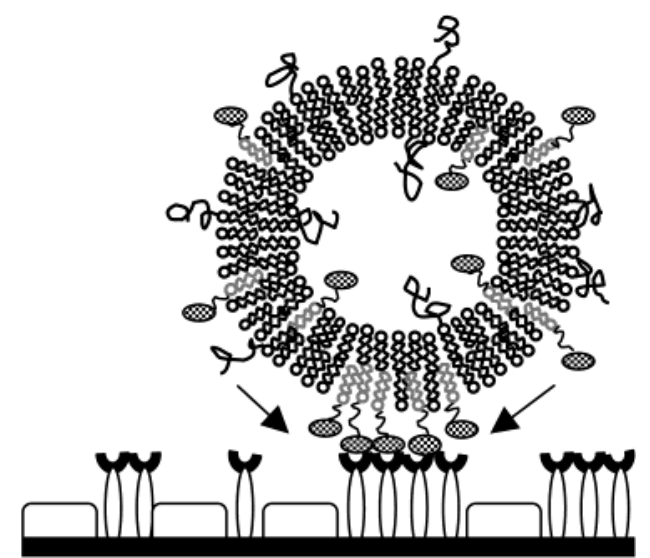

Figure 6. Schematic view of a RGD vesicle interacting with an integrin-covered surface.

clusters. ${ }^{33} \mathrm{As}$ a result, the probability of photodimerization under irradiation becomes much stronger than in thecase of noninteracting GUVs containing $2 \mathrm{~mol} \%$ RGD chalcone $\mathbf{5}$ or interacting ones containing 2 mol \% RGD stearyl 6 and $2 \mathrm{~mol} \% \mathrm{EO}_{3}$ chalcone $\mathbf{1}$. Thus dimerization can occur only in the case of the GUVs interacting with theintegrin surface.

In addition, the mechanism of photodimerization also explains why the GUV adhesion was reinforced after irradiation. The affinity for $\alpha_{11 \mathrm{~b}} \beta_{3}$ by the cyclic pentapeptide $(\approx 1 \mu \mathrm{M})$ is about $10^{3}$ times smaller than for $\alpha_{v} \beta_{3}$ (3 $\mathrm{nM}$ ) so the adhesion is expected to be weak. It is possible that the dimerization enforces binding to such an extent that even $\alpha_{11 b} \beta_{3}$ also binds strongly. If chalcone dimerization occurs, once the first integrin-RGD complex is formed, the probability for the second RGD of the dimer to bind is greater. The photoinduced dimer bearing two RGD ligands should thus have a stronger affinity for the integrin than the single RGD chalcone lipid.

In conclusion, the experiments show that the RGD chal cone 5 tends to segregatewithin theadhesi on plaques due to ligand-receptor binding as already observed for the case of cSA receptors. ${ }^{14}$ The RGD chal cone is free to move by lateral diffusion into the contact zone where the integrin surface is very closeto the membraneso that the binding reaction with theintegrin receptor can takeplace as schematically shown in Figure 6.

\section{Conclusion}

In this paper, we described a new approach tostudy the local formation of attractive domains during adhesion mediated by integrin/RGD ligand binding. Welabeled with fluorescent chalcones the hydrocarbon chains of lipid analogues exhibiting headgroups composed of a triethyleneglycol $\left(\mathrm{EO}_{3}\right)$ spacer both with and without exposed cyclic RGD-ligand. We showed that during adhesion the membrane forms zones of tight adhesion separated by unbound areas and that within the tight adhesion zones, arrays of pointlike pinning sites attributed to receptorligands pairs are formed.

Furthermore, the concentration of chromophore into small centers leads to a fast bl eaching which confirms the ligand segregation. The kinetics and the degree of the local fluorescence decrease are indicators of the local concentration of the chalcone in the adhesion zone of the membrane and enable the visualization of local quasicrystalline lipid clusters associated with the formation of

(33) Boulbitch, A.; Guttenberg, Z.; Sackmann, E. Biophys. J . 2001 $81,2743-2751$. 
adhesion plaques. Interestingly, we also observed that adhesion strength increases drastically upon irradiation. Such a property could be valuable for both studying the physicochemistry of the adhesion and designing new vectors for cell targeting.

The present study was also motivated by attempts to construct carriers for the effective transfer of vectors into cells. The incorporation of RGD-ligands into vesicles isexpected to improve their transfer into cells by binding to specific families of integrins which favor phagocytosis. The preparation of either oligomericRGD lipid ligands or membranes containing pure RGD lipid domains should improve the efficiency of the adhesion between liposomes and cell membranes.

Acknowledgment. Weare thankful to Martin Kantlehner for providing the cyclic pentapeptide c(-R(Pbf)GD-
$\left.\left(\mathrm{O}^{\mathrm{t}} \mathrm{Bu}\right) \mathrm{fK}-\right)$ and Matthias Tristl for giving access to the Langmuir film trough combined with fluorescence microscopy. We are grateful to the Humboldt F oundation for a postdoctoral fellowship to V.M.A., to the "F onds der chemischen Industrie". This work was performed within the framework of the French-German network funded by the Deutsche F orschungsgemeinschaft (DFG) and the Centre National de la Recherche Scientifique (CNRS).

Supporting Information Available: Figures showing Langmuir isotherms of a monol ayer composed of a lipid matrix, DMPC:chol:DMPE-PEG2000 (50:50:1) completed with 1:6 (2 $\mathrm{mol} \%, 2 \mathrm{~mol} \%$ ) or 1 (2 mol\%), evolution of emission intensity with OG concentration, and kinetics of fluorescence bleaching are available free of charge via the Internet at http:// pubs.acs.org.

LA026227K 